\title{
Corporate Strategy And The Social Networking Phenomena
}

\author{
Robert L. Johnson, University of Phoenix, USA
}

\begin{abstract}
The Social Networking (SN) phenomena has developed relatively overnight and is continuing to develop at an exponential pace. It allows for innovative new methods of disseminating and collecting information in ways never before dreamed possible by corporate executives. The rise of Social Networking is becoming a disruptive technology for traditional marketing and advertising medium such as radio, television, web page, and print media, creating new business opportunities for the entrepreneur within organizations of any size, and allowing lucrative treasure troves of corporate intelligence about how the customers feel about one's or a competitor's products or services. It means new executive leadership skills are now needed to take advantage of these new tools and developing corporate strategies. Those that do this well will be the winners in the market five years from now.
\end{abstract}

Keywords: Social Networking; Customer Service; Marketing; Disruptive Technology; Branding; Facebook; Twitter; Linkedin

\section{INTRODUCTION - THE RISE OF SOCIAL NETWORKING}

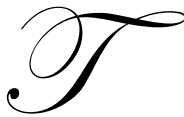

he Social Networking (SN) phenomena has developed relatively overnight and is continuing to develop at an exponential pace. "The first social network site, SixDegrees.com, was launched in 1997" (Bolar, 2009, p. 75). Today, there are a multitude of Social Networking sites, and they are changing, even rewriting the rules for marketing, communicating, customer service, market research, dating, socializing, and problem resolution. Some executives are embracing it to their advantage and some fear it to their hurt. It is evolving faster than the research and legislation can keep up with. It is not just the younger techie generation keeping the momentum going. "Recent studies have shown that 30 percent of Facebook users and 32 percent of MySpace users are older than 45" (Harris, 2008, II x). The ability to communicate instantly with ones friends or a group with homogenous interest or beliefs is having a profound impact how we communicate as a society.

Spreading like a pandemic virulent virus "people are connecting with one another in increasing numbers, thanks to blogs, Social Networking sites like MySpace and countless communities across the Web. Some companies are learning to turn this growing groundswell to their advantage" (Bernoff \& $\mathrm{Li}, 2008$, p. 36). It allows for innovative new methods of disseminating and collecting information in ways never before dreamed possible by corporate executives. It means new executive leadership skills are now needed to take advantage of these new tools and developing corporate strategies. Those that do this well will be the winners in the market five years from now.

The rise of Social Networking is becoming a disruptive technology for traditional marketing and advertising medium such as radio, television, web page, and print media, creating new business opportunities for the entrepreneur within organizations of any size, and allowing lucrative treasure troves of corporate intelligence about how the customers feel about one's or a competitor's products or services. "Go ahead and bellyache about blogs. But you cannot afford to close your eyes to them, because they're simply the most explosive outbreak in the information world since the Internet itself" (Baker, \& Green, 2008, p. 13). Marketing executives are learning to exploit this new social phenomena in order to gather business intelligence on how the masses truly feel about their products. Customer service departments are using social networks to spot a problem, to communicate with their customers and dispense help in a timely manner. Product developers are staying in close contact with their current 
and future customers as they work collaboratively to develop the right products with the right features. Companies are developing corporate pages for rapid two way communication with their employees. Employees are using Social Networking sites to facilitate work teams in a virtual environment. "Corporate Social Networking can provide transparency across departmental, affiliate and even geographic barriers, allowing the corporate community to connect and identify internal or external talent for projects, new roles and opportunities, while encouraging collaboration to solve functional and cross-functional problems" (Chivee \& Cowan, 2008, p. 43). This phenomenon is growing and not going away.

The demands of executives today in terms of leadership, marketing, customer service, product development, and advertising seem to have evolved into something quite different than what was just recently studied in business school textbooks. The business models and theories developed in earlier years do not always apply now. The younger demographics or "microwave" generation (we want it now) does not always respond the same way our parents or we did as a consequence of the new Social Networking age. New models and theories need to be researched and discovered. Soon, dissertations will start appearing on how to weave corporate strategy using texting, blogs, wikis, Facebook, podcasting, and so on. The Social Networking renaissance is here to stay. One either gets on board or gets left behind. Today, executives can go to a Social Networking site, look up their product, and sometimes get an unwelcome eye-opening of a serious negative public perception of their company completely undoing all the millions spent on building a brand image.

\section{WHAT IS CAUSING THIS SOCIAL EVOLUTION PHENOMENA?}

There are many reasons for this happening. For one, the internet has facilitated the compression of time and distance, while providing an easy low cost reach of the masses by the individual. Second, the technology has evolved with regards to smart phones such as the Blackberry and iPhone that give people portable or mobile connectivity. Often, people join a Social Networking site to be a part of a group, to feel connected, or gain access to information. This "involves finding, discovering, grouping, maintaining, sharing with other people who share a common back-ground, interests, [and] future" (Perey, 2008, 76). Social Networking sites make it easy to locate others who are likeminded as oneself.

Most people tend to have a need of belonging, or to be a part of something bigger than themselves. Often, this can include the "feeling of making a contribution to the betterment of the world, peace, [and demonstrating] social responsibility" (Perey, 2008, 76). It gives one a chance to feel good about themselves. For those who want to become product savvy, sometimes it can just be "increasing ones ability to make 'good' purchasing decisions, [or, for those who are product savvy] to influence the purchasing decisions of others in the community" (Perey, 2008, 76). One can now easily socialize, be a part of something bigger than themselves, gain product knowledge, or express their opinion to a large group without having to make an expensive investment or leave home.

In the corporate arena, Social Networking is rapidly becoming a new tool of knowledge management because it is a readily available means for companies to keep track of and disseminate up to date information to a lot of people in a short amount of time with minimal cost. In the future, there may be proprietary sites, or off the shelf software specifically designed for an organizations marketing, customer service, or product development team, and suppliers to be used as a knowledge management networking or collaborative tool to connect them for specific purposes. At present, everyone seems to be adapting to publically available SN sites for their use.

\section{WHAT IS A SOCIAL NETWORK?}

The term Social Networking can mean different things to different people such as a psychologist, social scientist, manager, education administrator, teenager, older adult, and so on. A social network is a rather loosely defined concept. For purposes of this paper "a social network is a configuration of people connected to one another through interpersonal means, such as friendship, common interests, or ideas" (Coyle \& Vaughn, 2008, p. 13). It is a technical means for anyone, friends, students, professional acquaintances, customers, and product developers to share information. A social network can be a blog, wiki, list server, or more such as Facebook, MySpace, and other tools appearing all the time. More often "Social Networking, as the phrase is being used in industry and in pop culture today, refers to the use of a specific type of Web site focused on the creation and growth of online social 
networks which allows users to interact" (Coyle \& Vaughn, 2008, p. 13). That interaction can be about anything, politics, product information, small talk among friends, discussions on popular topics, disseminate time sensitive information, customer complaints, emergency information, or any of topic mutual interest. The important thing, whatever it is being discussed or shared has corporate value as it provides a valuable source to market researchers or social scientists of what matters to the public or ones customers.

Social Networking can occur without one even realizing that is what they are doing. "Social searching occurs [for example] when a Facebook user looks up particular individuals he or she already knows or has become aware of via an offline connection in order to learn more about them. Social browsing, on the other hand, occurs when users try to find strangers online whom they would like to meet offline or online. Overwhelmingly, college students are using Facebook for social searching" (Coyle \& Vaughn, 2008, p. 14). Older adults use it to stay connected to grandchildren, fellow retirees, former military buddies, or perhaps join support groups for a multitude of medical ills. Corporate workers use Social Networking to distribute company specific information, product information, and disaster recovery information. Educators and entertainers use it to communicate class schedules, event show times, and academic program information. Just how pervasive is the usage of Social Networking sites? In a recent research effort it was discovered "the following nine SNWs report over 50 million registered users each: Facebook (124,000,000), Windows Live Spaces $(120,000,000)$, MySpace $(110,000,000)$, Habbo $(100,000,000)$, hi5 $(80,000,000)$, Friendster $(80,000,000)$, Orkut $(67,000,000)$, Flixter $(63,000,000)$, and Classmates.com $(50,000,000)$ " (Cardon, 2009, p. 96).

There are other tools for Social Networking other than a sites such as Facebook or My space, Classmates, etc., such as wikis and blogs. "A wiki is a collection of Web pages designed to enable users to freely create, modify, and edit Web page content. According to Platt (2007), wikis are used in organizations to provide affordable and effective knowledge management and information sharing" (Zhang, Zhu, \& Hildebrandt, 2009, 9. 116). They an be quite useful in project management for coordinating the activities of disparate departments or individuals. A wiki focuses "on the management of knowledge as an asset, which is essential for organizations, especially in the professional services industry where people and knowledge are the core assets of the organization" (Zhang, Zhu, \& Hildebrandt, 2009, 9. 116).

Another popular method of Social Networking that has become popular are blogs. "the term blog is a shortened version of the combination web and $\log$ and is most frequently equated to an online diary or Journal" (Alkhateeb, Clauson, Khanfar, \& Latif, 2008, p. 312). Bogs allow anyone their brief moment of fame on the internet. Citing Bonetta (2007), Alkhateeb, etal., (2008) note "a blog can be spearheaded by one individual, but is more commonly includes contributions by others, whether solicited or not, that can evolve into a dialogue" (Alkhateeb, etal., 2008, p. 312). Companies use blogs as a form of marketing, creating customer awareness, maintaining close contact with employees, a coordinating tool for project managers and producers, facilitating customer service, dissemination vital corporate information, and conducting knowledge management.

As a organizational (corporate, educational, medical, customer service) information dissemination tool many “. . . suggest that a blog is more effective than the traditional use of department newsletters or group emails. Not only does it aid in knowledge sharing but it also creates branding for individual members and departments or teams within the organization" (Zhang, Zhu, \& Hildebrandt, 2009, 9. 117). Companies use blogs and other Social Networking sites to monitor public opinion, respond to customers who are dissatisfied with the product or service received, inform customers about upcoming sales, new products, and answer requests for technical information or support.

The technology is constantly evolving into new methodologies and innovative new uses of that technology. It is almost impossible to forecast very far into the future the shape and direction of Social Networking other than it will continue to grow rapidly. The first movers to take advantage of the capabilities, knowledge management, information dissemination, and data mining opportunities of Social Networking will achieve a competitive advantage. This will require a mixed set of skills including technological, marketing, and the social sciences in addition to the already necessary leadership capabilities. 


\section{WHY THE FUSS?}

The world has changed almost overnight brought on by a marriage of the masses and Social Networking technology. To stay competitive, organizational leaders must develop strategies to "exploit the tendency of customers to use web-based methods to buy or recommend the kind of products and services your company supplies, or collaborate with each other in making decisions about them" (Stone, 2009, p. 120). This can be frightening to many brand managers and marketers who feel a lack of control when customers "no longer see themselves as passive respondents in their relationship with brands but active 'equals' who have the confidence to come into your space whether you have invited them to or not" (Needham, 2008, p. 61). One's best textbook marketing strategy, millions spent in building a brand via television, radio, and print media can be made obsolete overnight now that word of mouth "has been amplified by the second generation of websites such as Facebook and Myspace which has meant that both positive and negative brand recommendations can spread very quickly amongst existing and potential customers" (Needham, 2008, p. 61). The customer has gained power with their ability to rapidly disseminate either glowing product sales stimulating reports or sales damaging information with the clout of a major news channel with relatively inexpensive technology at their fingertips with a smart phone or an internet connection. No longer is a public relations executive worst nightmare seeing the Sixty Minutes crew show up at one's door. Now it is the teen ager who starts trashing your product for all the world to see on his or her smart phone and it does happen.

There are many reasons why Social Networking must be taken serious by organizational executives.. According to Bolar's (2009 research It has become "a resource for advertisers to promote their brands through wordof-mouth to targeted customers"; facilitates the "use of embedded advertisements in online videos"; . . "provide[s] a platform for new artists to show their profile" [and] in the education arena . . ."provide[s] a base for a new teacher-student relationship with more interactive sessions online" (p. 76). Participation in Social Networking gives one the chance to "participate in discussions, ... meet like-minded people, form and maintain communities" (Bolar, 2009, p. 79). Social Networking sites shrink the world by allowing individuals to have a direct connection to countless other individuals and groups with similar beliefs, fellow professionals, consumers, and organizations with mutual interest. They discuss technical information, and share their opinions on products and services. They only have to see the word "sucks" or "awesome" to instantly form an opinion without ever walking in the door or going to one's web site. Customers want relevant information, they want it now, and they want it from other users they feel a commonality with. They are becoming less interested in what the salesperson has to say.

\section{WHY SHOULD CORPORATE EXECUTIVES GET ON BOARD WITH SOCIAL NETWORKING?}

Social Networking sites have given consumers, students and educators, researchers, and other groups rapid and easy access to one another. "Empowered by online social technologies such as blogs, Social Networking sites like MySpace, user-generated content sites like YouTube and countless communities across the Web, customers are now connecting with and drawing power from one other" (Bernoff \& Li, 2008, p. 36). These individuals and virtual communities are growing in strength to become voices to be reckoned with. They are evolving into a greater power than whatever efforts or resources a company may expend on marketing or branding image they are trying to project. "This groundswell of people using technologies to get the things they need from one another, rather than from companies, is now tilting the balance of power from company to customer" (Bernoff \& Li, 2008, p. 36). Corporate executives must learn to cope with this shift in power.

This means corporate executives must learn to develop strategies to take advantage of the new technology tools available to them. Already taking advantage, "some use it to spot customer service problems almost immediately and respond far more quickly than their expensive customer call centers ever could" (Stewart, 2008, p. 17). Trouble spots can be pinpointed rapidly, and assistance or service can be dispatched immediately. Many forprofit companies use Twitter to communicate with their customers. Communications on Twitter, 140 characters or less, are called tweets. For example, "H\&R Block answers tax questions and responds to complaints from consumers who are unhappy with service they've received, Amazon.com pushes news about its sales, [and] Southwest Airlines informs followers customers about flight specials (Stewart, 2008, p. 17). Drug companies can communicate possible negative drug reactions. Doctors can tweet patients to remind them of their appointment, and politicians use Twitter to communicate their political agenda information to their constituents, and remind them to vote on election day. 
Just has it has changed social and dating mores, the Social Networking sites has changed the seller/consumer power structure. "The balance has been tipped in favor of the customer over the retailer, and profit margin percentage points are slipping lower and lower (Priluck, 2001)" (Griffiths, \& Howard, 2008, p. 69). It is easy for consumers to compare prices, product satisfaction, features, and post sale customer service on Social Networking sites. On the other hand, this is also an invaluable source for marketing managers and product designers to data mine and discover how the market perceives their product, and adjust their marketing strategy or product accordingly.

Notely (2008) seems to suggest that those who engage in Social Networking can have a higher level of social capital as a result. According to Woolcock (2001) as cited by Notely (2008) "International research has shown that higher levels of social capital are associated with better health, higher educational achievement, better employment outcomes and lower crime rates" (p. 23). Some see it as an opportunity to improve productivity while others view it as a threat to productivity. After all, how many managers and supervisors want to see their employees surfing and browsing Social Networking sites. However, in view of the research, with proper leadership, having a team of employees who know how to take advantage of Social Networking sites, and have a higher level of social capital, can result in having the team onboard that can integrate Social Networking into the company with positive results.

Departments across the company are using Social Networking sites as a mean of intra company communication. According to Leader and Cowan (2008),

Often sponsored by or set up by corporations in addition to or in tandem with intranet sites, corporate social networks allow company employees to engage in collaboration and business networking, acting as both internal and external brand ambassadors through their communications, preferences and online activities (p. 43).

The uses appear to provide a huge new frontier of innovative ways to communicate information to employees across geographically dispersed departments, with disparate customers and suppliers, product designers, and customer service providers. New technology is being developed at a rapid pace, new ways of taking advantage of that technology are being invented daily, and all the while legislation has yet to catch up to any unforeseen legal issues that may arise such as privacy, identity theft and other cyber crime, and loss of control of proprietary information. Organizational leaders must move quickly, but carefully.

Human resource executives are increasingly turning to Social Networking sites to locate new talent. LinkedIn is one site that has become popular among business professionals as a form of networking, and it is used by both recruiters and job hunters alike. "In the recruiting field, it is becoming more commonplace to use Social Networking sites as places to screen candidates before reading a resume" (Jannsen, 2009, p. 1672). This has led to a new concept called e-professionalism (Cain, 2007). One must always keep in mind that anything sent electronically can have consequences far beyond ones original intent. Once your personal information or communication is put on the internet, it is there forever, can be forwarded to thousands or millions in seconds, and is un-retrievable. For almost any profession [HR, education, medical, business] this can create "legal and ethical implications of using online postings in admissions, discipline, and ... how online personas may blend into professional life (Cain, 2007, p. 1). If one is in the slightest doubt if one is posting too much information about one's self, do not post. Be one hundred percent e-professional one hundred percent of the time.

\section{Social Networking and Marketing}

In the marketing arena "new communications vehicles such as the Internet, Social Networking, and mobile devices are gaining scale and delivering effective results. Meanwhile, classic media such as television have become, at a minimum, [relatively] much more costly" by comparison (Court, 2009, II 149-151). This has required a serious reallocation of resources from traditional marketing mixes. A lot of experimenting will be required to get it right, however, some dissertation and business research will allow for more educated decision making tools than just trial and error.

As Social Networking is changing how marketers develop their strategy, it is functioning somewhat as a disruptive technology. "Absolute price leadership is not necessary if the differentiation of the offering is clearly 
communicated and accepted, but pricing must be competitive and reflect the value added by the retailer" (Griffiths, \& Howard, 2008, p. 69). That communication of differentiation can be achieved via the many alternative Social Networking outlets available. It allows a collaboration of customer and research development personnel to build in the features that the buyers want. "It lets consumers come up with their own ideas and product designs as well as ways to make them happen and bring the product to life in the market place" (Needham, 2008, p. 61). It actually takes a lot of the guess work out of what the customer wants. It allows a two way communication between the consumer and the product designers early in the development process never before dreamed possible which can mean getting it right the first time. "This has injected fresh and different ways of thinking and has been incredibly disruptive, producing ideas that they and their agencies had not considered" (Needham, 2008, p. 61). Yet, with disruption comes opportunity. It is a matter of figuring out how to exploit it.

Because the disruptive influence of Social Networking is creating confusion with traditional marketing efforts, "the traditional distinctions between producer and consumer, and between mass communication and individual communication are dissolving, and with these, traditional models of media management" (Berthon, 2008, p. 6-7). Word of mouth and the opinions of the individual now matter, often more than the corporate media blitz. With Social Networking sites one can be easily heard by thousand or hundreds of thousands. This has had a significant impact on radio, television, and print media revenues as potential customers are relying less and less on them as a source of information.

\section{Social Networking and Customer Service}

Social Networking has inadvertently found one bit of a niche in the realm of customer service. Recently, when Comcast's customers were without internet service for three days and failing to get results via the customer service team, customers complained bitterly on blogs and Twitter. Their voices were so loud it was noticed within 20 minutes by a Comcast executive who then led a timely resolution (Stewart, 2008). Now, companies are using these SN sites to stay current on when, where, and what problems develop, and dispatch repair crews in a timely manner. The alternatives for a company not doing this are not good. Companies using Social Networking to omprove their customer service will move ahead of their competitors.

The customer has gained significant power with the advent of Social Networking. If a customer is unhappy with a company's customer service, they can complain on a Social Networking site and soon, if any of their friends have had a similar negative experience, they can add their own story which then connects to their friends and so on. Soon, thousands upon thousands of disgruntled customers are complaining in a public forum where news agencies hungry for a good story can easily net the information and write an expose on the company. Today, customers are ". . defining their own perspective on companies and brands, a view that's often at odds with the image a company wants to project" (Bernoff \& Li, 2008, p. 36). Today, the individual customer has clout via the ability to have their complaint heard by a vast crowd on the internet and in a short amount of time. This causes executives to be fascinated with its potential marketing capability and horrified by its potential to create a negative groundswell against the company at the same time. The little guy now has a voice. As noted by Comm and Burge (2009),

The quality of our lives is only as good as the quality of our relationships. Interactions shape not only our personal lives but also our professional lives. With the continuing advancements in technology, no longer are our social circles necessarily limited by whom we meet in person: the advent of Social Networking technologies such as Facebook, My Space, and Twitter has advanced relationship building into cyberspace (p. 1).

The control hierarchy has changed placing unheard of power in the hands of consumers. The customer is starting to dictate brand image to the chagrin of marketing executives. However, by embracing this power, taking advantages of the Social Networking technologies and "by focusing on the customer and kind of dialogue and information they feel customer[s] wants, some companies are making good progress in real-time customer management" (Stone, 2009, p. 101). One must not fight the currents and drown, but lean to take advantage of it, go with the flow, and enjoy the ride. 


\section{Social Networking and Educational Institutions}

One group of organizations taking advantage of the Social Networking phenomenon among their customers are educational institutions. "For some college students, Social Networking sites (SNS) such as Facebook and MySpace have become their principal means of communication" (Harris, 2008, p. 40). While attempting to exploit the ability of these sites to stay connected with their students, colleges must remember that there are privacy issues to consider as self disclosure and student personal information can be visible in the public forum.

However, Social Networking sites can be used by education administrators to publish general class schedules, announce events, communicate academic program information, and recruit students. Some are starting to experiment integrating pedagogical activities into the technology. The student demographics does not seem to matter as to whether or not the student population is connected. "A recent study by the University of Minnesota found that low-income students are just as technologically proficient as their counterparts and credit SNS [Social Networking sites] for teaching them technology skills, as well as creativity, and providing exposure to diverse views" (Harris, 2008, p. 40). More over ". . . the groundswell phenomenon is hardly limited to the United States" (Bernoff \& $\mathrm{Li}$, 2008, p. 42) as the idea is spreading around the globe. Additionally, many new research opportunities have opened up in the social sciences as dating and socializing habits among students have been drastically altered.

Social Networking sites do have their drawbacks in the educational arena as well as business. On the negative side "the influence of SNS on privacy issues, credibility and the breeding of inappropriate relationships and behavior has posed technological dilemmas in which more universities will have to continually work to develop institutional online Social Networking policies" (Harris, 2008, p. 40). With almost every cell phone having a camera or even a video capability, one must remember, as the colloquial saying is not so true anymore, what happens in Vegas no longer stays in Vegas. It can soon be on the world wide web via many of the Social Networking sites within a matter of minutes and be there forever impacting one's career and political aspirations years later.

Nevertheless, regardless of the new management issues and challenges, on the positive side, this will create new opportunities in ways unimagined in the recent past. According to research, Social Networking is not something to be considered frivolous, in fact quite the opposite. "Such findings suggest that the social aspect can increase students' persistence in their college studies and their ability to achieve at higher levels" (Harris, 2008, p. 40). Anything that can increase student retention is causing administrators to take note. It is becoming increasingly important for today's new managers to possess the technical skills conducive to conduct business in a Social Networking environment to be hired for today's better jobs. An educational setting is the safest environment for obtaining those skills. Social Networking appears to be here to say and it is a matter of how to integrate and take advantage of it, not whether to do so or not.

\section{Social Networking and Healthcare}

Social Networking sites can assist healthcare practitioners and consumers. For example, "if properly leveraged, blogs, podcasts, social media and wikis can be used by pharmaceutical companies to actively engage physicians and patients and strengthen collaborative efforts" with drug companies (Alkhateeb, Clauson, Khanfar, \& Latif, 2008, p. 316-317). The big concern for many on both sides is privacy and identify theft issues as SN sites are widely used now to communicate health care information, promote public health issues, dispense advise, and engage patients in support groups (Editorial, 2008, p. 89). As with anything, with time and experience, drug and insurance companies, care providers, and patients will learn to guard private medical information, and new legislation will catch up to the advances in technology.

Information means power, and one must wonder how much information and therefore power the medical profession is willing to give up and imbue to its customers or patients. These concerns should keep doctoral students busy for years to come as they conduct Social Networking research for their dissertations with the goal of developing innovative solutions for improved patient care. "The phenomenon has already reached the business world, where social networks have been created to enable professionals in industries such as advertising and finance to liaise virtually with colleagues and use online forums, email lists and message boards to post business information" (Editorial, 2008, p. 89). One component to quality health care is timely information among all parties 
and Social Networking facilitates that. Social Networking should bring about an improvement of health care through a bringing together of patients, medical professionals, insurance carriers, drug companies, legislators, and medical equipment suppliers to coordinate, communicate, and balance the needs of the various stakeholders and achieve positive outcomes for the future of patient care.

\section{WHERE ARE WE HEADED?}

For the near and foreseeable future, Social Networking will continue to grow at a rapid pace creating a social and cultural change in information sharing and collaboration among people and groups with a common concern. It has and will continue to change the social fabric of organizations and user of all ages. It has impacted dating, marketing, finding old college or high school friends, acted as a means of easy broadcasting of emergency instructions, dissemination of product reviews, enhancing customer service connectivity, group or event schedule coordination, and sharing personal information, the latter which has created one negative; and that is identity theft and cyber stalking. It is requiring new job skills for today's knowledge workers, new legislation to properly control its use, and caution on the part of the user as to how much information to disclose.

What is a social network is loosely defined and will continue to require updating as new forms of networking sites and new technologies continue to develop and evolve. For now it can broadly be defined "... as an internet-based environment that requires membership for participation whereby membership facilitates a relationship through which resources (both material and immaterial) can be mobilised" (Notley, 2008, p. 20-21). That definition can be expected to evolve over time. Social Networking is changing how marketers ply their trade, product developers determine what features consumers want, educational institutions communicate class schedules, entertainment venues provide the latest show times, and airlines keep flight schedule and gate information constantly up to date

With the advent of smart-phones, during times of a company or civil emergency, a manager no longer needs to call a multitude of individuals, they only need to send a tweet using Twitter.com or other SNS and can instantly connect with their particular following. Since one bad customer experience can lead to a loss of company reputation as one tells all their friends who in turn tell all their friends, and the ordeal snowballs into a public relations nightmare, organizational leaders must learn to use $\mathrm{SN}$ sites to turn the tide and create a positive corporate image. Those strategies are not yet taught in business schools but one can expect them to start doing so in the foreseeable future.

Social Networking cuts across all strata of demographics and industries "from media to health care, from financial services to consumer packaged goods ... [resulting in] a cultural shift in a customercentric direction ... [that is frightening executives] because they require managers to embrace an unknown communications channel, one that responds poorly to attempts to control it" (Bernoff \& Li, 2008, p. 40). Drastically challenging and changing long held marketing strategy tenets, now days "most marketing plans therefore try to meet their objectives costeffectively by using a mix of traditional and new vehicles, with the latter typically accounting for 10 to 15 percent of spending" (Court, 2009, II 151-152). As managers gain experience and experiment with various mixes, it may be the percentage spent on Social Networking increases significantly.

No longer relying on organizational advertising, or print media to obtain customer reviews, "consumers are providing significant advisory services to each other using rating and advice web sites such as ePinions. They are even redesigning and remanufacturing products for themselves, and others, and using Internet technologies to distribute their offerings" (Berthon, 2008, p. 6-7). The is bringing about a fundamental power shift in favor of the customer that has senior executives learning to cope with. It is even creating some unusual leadership, knowledge management, and communication flows inside the companies and questions on how to manage it.

The industrial revolution shrunk the world, the electronic age has compressed time, and Social Networking has greatly enlarged the audience and shifted the power structure in favor of the customer or individual. Leaders need to master the technology and concepts of Web 2.0 now. "The term 'Web 3.0' was coined by John Markoff of the New York Times in 2006. It refers to a possible next generation of Internet-based services" (Stone, 2009, p. 113). At the rate of technological advancement, Web 3.0 is not that far around the corner. When it arrives, those still 
struggling with Web 2.0 capabilities will be hopelessly left behind, obsolete, and probably out of business. The technological adapters will be the survivors in the future. While it is a bit like hitting a moving target in a game with constantly changing rules, and legislative protections playing catch up, organizational strategies must still be put into place to accommodate Social Networking.

\section{CONCLUSION}

Business, health care, and education are not the only ones being impacted as Social Networking is becoming more disruptive in other areas. Even the gambling industry has taken a disruptive Social Networking hit. "Firms such as Betfair, the world's largest sports betting exchange, permit customers to make, rather than have to take, their own prices (in the form of betting odds), and therefore represent a real competitive threat to incumbent firms and odds makers" (Berthon, 2008, p. 6-7). The legal issue of making and taking bets on Facebook and Twitter have yet to be decided in the courts. Laws are slow to catch up with technology and there are a host of legal issues that will need to be addressed by legislatures as to what is permissible on a Social Networking site and what it not.

It is becoming "hard to understand why more companies and the nonprofits don't use this powerful communication tool to monitor public comment about their brand and push their marketing message" (Stewart, 2008, p. 17). Soon, there will be business courses on how to take advantage of Social Networking to lead, communicate, track service issues, improve medical care, and dissertations will be written on the research of how to tap into the advantages and develop profitable strategies. As an organizational recruiting, communications and problem solving tool, "corporate Social Networking can provide transparency across departmental, affiliate and even geographic barriers, allowing the corporate community to connect and identify internal or external talent for projects, new roles and opportunities, while encouraging collaboration to solve functional and cross-functional problems" (Leader \& Cowan, 2008, p. 43).

Social Networking is here to stay and for the "long-term, engaging with the groundswell is the best possible way to promote customercentric thinking within companies, because it confronts managers with very direct evidence of how customers think. There is no hiding" from it (Bernoff \& Li, 2008, p. 42). It is either get on board or get left behind. Business, health care, education administrators, and even politicians must now learn the art of eprofessionalism, how to manage their customers, clients, or constituents in real time, and learn to develop strategies using Social Networking as a significant component of their brand imaging, customer service management, marketing strategy, knowledge management, and product or service design process. Executive leaders must embrace it and lean to tame it for their benefit or be overtaken and crushed by it. Decisions must not only be made after considering their impact on the bottom line; as espoused in business schools; but for how will it play in the Social Networking sites. That impact on the SN sites has a direct impact on the bottom line.

\section{AUTHOR INFORMATION}

Dr. Robert L. Johnson earned his MBA in Finance with National University of San Diego and his DBA in Finance with Nova Southeastern University of Fort Lauderdale, Florida. He is currently the Associate Vice President of Academic Affairs for the University of Phoenix. E-mail: robert.johnson@ phoenix.edu

\section{REFERENCES}

1. Alkhateeb, F., Clauson, K., Khanfar, N., \& Latif, D. (2008, September). Legal and regulatory risk associated with Web 2.0 adoption by pharmaceutical companies. Journal of Medical Marketing, 8(4), 311318.

2. Baker, S., \& Green, H. (2008, February 21). Social Media Will Change Your Business. BusinessWeek Online, 13

3. Bernoff, J., \& Li, C. (2008). Harnessing the Power of the Oh-So-Social Web. MIT Sloan Management Review, 49(3), 36-42.

4. Berthon, P., Pitt, L., \& Campbell, C. (2008). Ad Lib: When Customers Create The Ad. California Management Review, 50(4), 6-30. 
5. Bolar, K. (2009, January). Motives Behind the Use of Social Networking Sites: An Empirical Study. ICFAI Journal of Management Research, 8(1), 75-84.

6. Cain, J. (2008). Online Social Networking Issues Within Academia and Pharmacy Education. American Journal of Pharmaceutical Education, 72(1), 1-7.

7. Cardon, P. (2009, March). Online Social Networks. Business Communication Quarterly, 72(1), 96-97.

8. Comm, J., \& Burge, K. (2009). Twitter Power. Business Book Review Library, 26(35), 1-11.

9. Court, D. (2009). The downturn's new rules for marketers. McKinsey Quarterly, (1), 66-75.

10. Coyle, C., \& Vaughn, H. (2008, Summer2008). Social Networking: Communication revolution or evolution?. Bell Labs Technical Journal, 13(2), 13-17. 2008). Editorial. Journal of Visual Communication in Medicine, 31(3), 89-90.

11. Fernandez, J. (Sept 4, 2008). Facebook: Balancing the book. Marketing Week, p.23.

12. Griffiths, G., \& Howard, A. (2008, Winter2008). Balancing clicks and bricks - strategies for multichannel retailers. Journal of Global Business Issues, 2(1), 69-75.

13. Harris, K. (2008, October 16). Using Social Networking Sites as Student Engagement Tools. Diverse: Issues in Higher Education, 25(18), pp. 40,40.

14. Jannsen, M. (2009, September 15). Social Networking and e-Professionalism. American Journal of HealthSystem Pharmacy, 66(18), 1672.

15. Leader-Chivée, L., \& Cowan, E. (2008, October). Networking the Way to Success: Online Social Networks for Workplace and Competitive Advantage. People \& Strategy, pp. 40-46.

16. Needham, A. (2008). Word of mouth, youth and their brands. Young Consumers, 9(1), 60-62.

17. Noticeboard. (2009, June). Primary Health Care, Retrieved September 23, 2009, from Academic Search Complete database.

18. Notley, T. (Sept 2008). Online network use in schools: social and educational opportunities.(Essay). Youth Studies Australia, 27, 3. p.20(10).

19. Stewart, J., (2008). Twitter time: How companies are using and responding through the Social Networking tool. Public Relations Tactics, 10(15), 17.

20. Stone, M. (2009). Staying customer-focused and trusted: Web 2.0 and Customer 2.0 in financial services. Journal of Database Marketing \& Customer Strategy Management, 16(2), 101-131.

21. Perey, C. (2008, December). Mobile Social Networking: The brand at play in the circle of friends with mobile communities representing a strong opportunity for brands. International Journal of Mobile Marketing, 3(2), 75-79.

22. Zhang, A., Zhu, Y., \& Hildebrandt, H. (2009, March). Enterprise networking web sites and organizational communication in Australia. Business Communication Quarterly, 72(1), 114-119. 